Original Article

\title{
Effects of community-based rehabilitation program on activities of daily living and cognition in elderly chronic stroke survivors
}

\author{
Young-Ju PARK, MS, OT ${ }^{1)}$, Chun-YeOP LeE, MS, OT ${ }^{2 *}$ \\ 1) Department of Occupational Therapy, Sehan University, Republic of Korea \\ 2) Department of Occupational Therapy, Kaya University: 208 Samgye-ro, Gimhae-si, \\ Gyeongsangnam-do 50830, Republic of Korea
}

\begin{abstract}
Purpose] The aim of this study was to examine the effects of community-based rehabilitation program in chronic stroke patients. [Subjects and Methods] Eleven subjects received community-based rehabilitation program ten times for ten months. The main outcome measures were the Modified Barthel Index score for activities of daily living and the Korean Mini-Mental State Examination score for cognition. [Results] The results of the study demonstrated that the community-based rehabilitation program improved activities of daily living performance and cognition significantly. [Conclusion] Based on the study results, the community-based rehabilitation program is an effective method for improving activities of daily living performance and cognitive function in elderly patients with chronic stroke.

Key words: Community-based rehabilitation, Elderly, Stroke
\end{abstract}

(This article was submitted Jul. 27, 2016, and was accepted Sep. 26, 2016)

\section{INTRODUCTION}

Stroke is one of the main causes of mortality and disability among the elderly ${ }^{1)}$. Stroke results in serious complex functional problems in many areas, especially cognitive and physical impairments that significantly limit their activities of daily living $(\mathrm{ADLs})^{2}$. Eventually, stroke survivors after returning to living in the community after discharge would need to attend alternative rehabilitation program ${ }^{3)}$. Most stroke survivors experience several limitations to participate their community ${ }^{4}$, particularly ADL performance and cognition ${ }^{5}$.

Community-based rehabilitation (CBR) is an effective method for individuals with stroke and utilizes therapeutic resources from community. Therapists are important resources because they can conduct effective CBR programs and counsel those with stroke ${ }^{6}$. In South Korea, CBR programs have been conducted gradually for stroke patients ${ }^{7}$. Furthermore, most CBR programs were focused on motor recovery ${ }^{8)}$ or cognition for stroke ${ }^{9)}$. Further evidence regarding the effectiveness of CBR programs in various areas of rehabilitation of the elderly are needed. Therefore, the aim of this study was to investigate the effects of the CBR program on ADL performance and cognition, and to provide evidence for implementing the CBR program for elderly patients with chronic stroke.

\section{SUBJECTS AND METHODS}

This study was carried out from April 2015 to January 2016, and the community-dwelling, elderly chronic stroke survivors were recruited at the J City Health Center. Every participant was required to meet the following inclusion criteria: (a) stroke identifiable by a medical doctor, (b) age $\geq 65$ years, (c) 5 years post stroke, and (d) intact cognitive function for understanding

\footnotetext{
*Corresponding author. Chun-Yeop Lee (E-mail: bommm81@naver.com)

(C)2016 The Society of Physical Therapy Science. Published by IPEC Inc.

This is an open-access article distributed under the terms of the Creative Commons Attribution Non-Commercial No Derivatives (by-nc-nd) License $<$ http://creativecommons.org/licenses/by-nc-nd/4.0/>.
} 
program instructions. Participants were excluded if they (a) had any other neurological diseases except stroke, or (b) did not provide consent. This study was approved by the Inje University's Institutional Review Board.

The CBR program comprised ADL (exercise) and cognition (crafts), and that was conducted in an auditorium of the J Health Center with group setting. The CBR program was summarized in Table 1. The CBR program performed for 2 hours in every session, once per month for ten months by two occupational therapists and four well-trained exercise assistants. The Modified Barthel Index (MBI) score ${ }^{10}$ was used to assess ADL performance. The Korean Mini-Mental State Examination (MMSE-K) score ${ }^{11)}$ was used to assess cognitive function. The statistical analyses in this study were performed using SPSS 22.0. Demographics and clinical characteristics of the subjects were analyzed by using descriptive statistics. The mean differences between pre-and post-intervention scores were analyzed by using the Wilcoxon signed rank test, and the significance level was at $\mathrm{p}<0.05$.

\section{RESULTS}

Demographics and clinical characteristics of the subjects are summarized in Table 2. After applying the CBR program, as shown in Table 3, the MBI score significantly improved from $42.8 \pm 25.6$ to $63.2 \pm 22.2(\mathrm{p}<0.05)$. Further, the MMSE-K score showed a significant improvement from $19.3 \pm 5.1$ to $21.5 \pm 4.7(\mathrm{p}<0.05)$.

\section{DISCUSSION}

This research aimed to identify the effect of CBR on ADL performance and cognition in elderly patients with chronic stroke. We recruited patients treated at J City Health Center. It needs to be considered the possibility of any biased factor between interventions since the interventions were done once a month. Therefore we exclude subjects if they have attended any other treatment above this program. Fifteen subjects started on CBR program and 11 subjects finished for this reason.

The stroke survivors have dysfunction mentally as well as physically ${ }^{12}$. Therefore, we consisted of motor and cognition

Table 1. General characteristics of subjects

\begin{tabular}{|c|c|c|}
\hline \multicolumn{2}{|c|}{ Characteristics } & $\mathrm{N}(\%)$ \\
\hline \multirow{2}{*}{ Gender } & Male & $4(36.4)$ \\
\hline & Female & $7(63.6)$ \\
\hline \multirow{3}{*}{ Age (years) } & $65-74$ & $8(72.8)$ \\
\hline & $75-84$ & $2(18.2)$ \\
\hline & 85 and above & $1(9.1)$ \\
\hline \multirow{2}{*}{ Lesion type } & Hemorrhagic & $4(36.4)$ \\
\hline & Infarction & $7(63.6)$ \\
\hline \multirow{2}{*}{ Paretic side } & Right & $6(54.5)$ \\
\hline & Left & $5(45.5)$ \\
\hline \multicolumn{2}{|c|}{ Disease duration (years) } & $7.4 \pm 0.9^{*}$ \\
\hline
\end{tabular}

Table 3. Comparison of pre and post-intervention scores of MBI and MMSE-K

\begin{tabular}{lcc}
\hline & Pre-intervention & Post-intervention \\
\hline MBI & $42.8 \pm 25.6$ & $63.2 \pm 22.2^{*}$ \\
MMSE-K & $19.3 \pm 5.1$ & $21.5 \pm 4.7^{*}$ \\
\hline
\end{tabular}

MMSE-K: Korean Mini-Mental State Examination, MBI: Modified Barthel Index, Mean $\pm \mathrm{SD},{ }^{*} \mathrm{p}<0.05$

Table 2. CBR program

\begin{tabular}{cll}
\hline Session & ADL (Exercise) & Cognition (Craft) \\
\hline 1 & ROM exercise with towel & Soap \\
2 & ROM exercise with theraband & Gardening \\
3 & Static balance training & Painting \\
4 & Dynamic balance training with ball & Paper \\
5 & Fall prevention (OEP) & collage \\
6 & Locomotion training & Wire \\
7 & Fall prevention (OEP) & Rubber band \\
8 & Transfer training & Beads \\
9 & Fall prevention (OEP) & Mosaic \\
10 & Dressing training & Setting plans \\
\hline
\end{tabular}

ADL: Activities of Daily Living, CBR: Community-Based Rehabilitation, OEP: Otago Exercise Program 
program in every session for ten months. This study was the first trial in application of motor and cognition for CBR program at the same time for elderly patients in South Korean. For this reason, this study would have more novelty than other studies for CBR. The MBI score was used to evaluate ADL performance and the MMSE-K score was used to assess cognition. The results of this study showed that the CBR program significantly improved ADLs and cognition. There are similar findings in previous studies about the effects of CBR program with stroke survivors on ADLs ${ }^{13)}$ and cognition ${ }^{14)}$. Comprehensive rehabilitations are needed for stroke to adapt their community. The CBR program has been centered around Health Centers and shown positive effects by various approach in South Korea ${ }^{15)}$. There are several limitations of this study. The sample size was small, therefore its results may not be generalizable to the entire population of elderly with chronic stroke. Further, various intervention programs should be considered along with exercise and crafts.

\section{ACKNOWLEDGEMENT}

This paper was supported by the Sehan University Research Fund in 2016.

\section{REFERENCES}

1) Salter K, Jutai JW, Teasell R, et al.: Issues for selection of outcome measures in stroke rehabilitation: ICF Body Functions. Disabil Rehabil, 2005 , 27: 191-207. [Medline] [CrossRef]

2) Dam M, Tonin P, Casson S, et al.: The effects of long-term rehabilitation therapy on poststroke hemiplegic patients. Stroke, 1993, 24: 1186-1191. [Medline] [CrossRef]

3) Song JY: Effect of a group self-exercise program on quality of life and motor functions after stroke. PTK, 2008, $15: 20-29$.

4) Mudzi W, Stewart A, Musenge E: Community participation of patients 12 months post-stroke in Johannesburg, South Africa. Afr J Prim Health Care Fam Med, 2013, 5: 1-9. [CrossRef]

5) Kim K, Kim YM, Kim EK: Correlation between the activities of daily living of stroke patients in a community setting and their quality of life. J Phys Ther Sci, 2014, 26: 417-419. [Medline] [CrossRef]

6) Lee HS: A plan of activation of health care center in community based rehabilitation. J Spec Edu Rehabil Sci, $2008,47: 47-64$.

7) Lee HS, Ann CS, Kim MC, et al.: Patient preference for community-based rehabilitation programs after stroke. J Phys Ther Sci, 2011, 23: 137-140. [CrossRef]

8) Pang MY, Harris JE, Eng JJ: A community-based upper-extremity group exercise program improves motor function and performance of functional activities in chronic stroke: a randomized controlled trial. Arch Phys Med Rehabil, 2006, 87: 1-9. [Medline] [CrossRef]

9) Jeong WM, Lee DY, Ryu SH, et al.: Focused effects of a group cognitive rehabilitation therapy on mild dementia patients in a community-focused occupational therapy intervention process model. J Korean Soc Occup Ther, 2008, 16: 1-17.

10) Shah S, Vanclay F, Cooper B: Improving the sensitivity of the Barthel Index for stroke rehabilitation. J Clin Epidemiol, 1989, 42: 703-709. [Medline] [CrossRef]

11) Kwon YC, Park JH: Korean version of Mini-Mental State Examination (MMSE-K). Part I: Development of the test for the Elderly. J Korean Neuropsychiatr Assoc, 1989, 28: 125-135.

12) Wolfe CD, Crichton SL, Heuschmann PU, et al.: Estimates of outcomes up to ten years after stroke: analysis from the prospective South London Stroke Register. PLoS Med, 2011, 8: e1001033. [Medline] [CrossRef]

13) Choi HS: Effects of a community-based rehabilitation program on cognitive status, ADL, and occupational performance/satisfaction of old patients. Bull Dongman Health Coll, 2002, 20: 185-193.

14) Kwon JS, Yuk J, Byun EM: The effect of home based cognitive rehabilitation program on stroke patients. J Korean Soc Occup Ther, 2009 , 17 : 39-48.

15) Lee HY, Sagong B: The effect of home based rehabilitation program on activities of daily living, self-efficacy, quality of life among chronic stroke patients. J Spec Edu Rehabil Sci, 2015, 54: 275-290. 